\title{
Review
}

\section{Exploiting death: apoptotic immunity in microbial pathogenesis}

\author{
DS Ucker*,1
}

Innate immunity typically is responsible for initial host responses against infections. Independently, nucleated cells that die normally as part of the physiological process of homeostasis in mammals (including humans) suppress immunity. Specifically, the physiological process of cell death (apoptosis) generates cells that are recognized specifically by viable cells of all types and elicit a profound transient suppression of host immunity (termed 'innate apoptotic immunity' (IAI)). IAI appears to be important normally for the maintenance of self-tolerance and for the resolution of inflammation. In addition, pathogens are able to take advantage of IAl through a variety of distinct mechanisms, to enable their proliferation within the host and enhance pathogenicity. For example, the protist pathogen Leishmania amazonensis, at its infective stage, mimics apoptotic cells by expressing apoptotic-like protein determinants on the cell surface, triggering immunosuppression directly. In contrast, the pathogenic bacterium Listeria monocytogenes triggers cell death in host lymphocytes, relying on those apoptotic cells to suppress host immune control and facilitate bacterial expansion. Finally, although the inhibition of apoptotic cell death is a common attribute of many viruses which facilitates their extended replication, it is clear that adenoviruses also reprogram the non-apoptotic dead cells that arise subsequently to manifest apoptotic-like immunosuppressive properties. These three instances represent diverse strategies used by microbial pathogens to exploit IAl, focusing attention on the potency of this facet of host immune control. Further examination of these cases will be revealing both of varied mechanisms of pathogenesis and the processes involved in IAI control.

Cell Death and Differentiation (2016) 23, 990-996; doi:10.1038/cdd.2016.17; published online 4 March 2016

Facts:

- Apoptotic cells are potently immunosuppressive, eliciting a repertoire of immunomodulatory responses termed 'innate apoptotic immunity' (IAI).

- IAI is triggered upon recognition of protein determinants externalized on the apoptotic cell surface, independent of phagocytosis.

- IAI is exploited by pathogens to modulate host immunity, thereby enhancing their pathogenicity.

- Pathogens use distinct strategies for the exploitation of IAI. Among these are apoptotic subversion, apoptotic mimicry, and death reprogramming.

\section{Open Questions:}

- How widespread is the exploitation of IAI among the varied strategies of pathogenesis used by different pathogens?

- Are other mechanisms (beyond apoptotic subversion, apoptotic mimicry, and death reprogramming) used by pathogens to exploit IAI?

- What are the necessary and sufficient conditions (including expression of apoptotic-like determinants) that pathogens use for triggering IAI?
Infections by pathogenic microorganisms elicit host immune responses, which crucially limit those infections. Host innate immunity (especially including inflammation) is responsible typically for initial responses. At the same time, pathogens use various strategies to evade host immunity. Indeed, host immunity often is compromised by infection and associated stresses (see, for example, Lederer et al. ${ }^{1}$ ). Among specific strategies of immune evasion used by pathogens, some involve the exploitation of the potent immunosuppressive responses elicited normally by apoptotic cells.

Cells die physiologically throughout life in metazoans. This physiological process (apoptosis) serves to eliminate cells that have become functionally inappropriate, and assures their rapid clearance in a manner that does not elicit inflammatory and other immune responses. ${ }^{2,3}$ During the process of apoptosis, new determinants for recognition appear on the dying cell surface..$^{4-6}$ Recognition-dependent signaling leads both to the rapid engulfment and clearance of the apoptotic corpse ${ }^{7}$ and to a profound repertoire of suppressive immune (especially anti-inflammatory) responses, which we have termed 'innate apoptotic immunity' $\left(\mathrm{IAI} \mathrm{I}^{8}\right)$.

Apoptotic cell clearance occurs via a process of stimulated phagocytosis (macropinocytosis), which is characterized by the uptake of fluid-phase markers (such as Lucifer Yellow) and its sensitivity to inhibition by amiloride. ${ }^{7}$ The exposure of

\footnotetext{
${ }^{1}$ Department of Microbiology and Immunology, University of Illinois College of Medicine, Chicago, IL 60612, USA

*Corresponding author: D Ucker, Department of Microbiology and Immunology, University of Illinois College of Medicine, 835 South Wolcott, Chicago, IL 60612, USA. Tel: +1 (312) 413 1102; Fax: +1 (312) 413 7385; E-mail: DUCK@UIC.EDU

Abbreviations: E1B 19K, Adenovirus $19 \mathrm{kDa}$ death-inhibitory protein encoded by the E1B gene; GAPDH, Glutaraldehyde 3-phosphate dehydrogenase; IAI, Innate apoptotic immunity; IL, Interleukin; PS, Phosphatidylserine; TNF $\alpha$, Tumor necrosis factor- $\alpha$; TGF $\beta$, Transforming growth factor- $\beta$

Received 02.11.15; revised 26.1.16; accepted 27.1.16; Edited by G Kroemer; published online 04.3.16
} 
Box 1 The repertoire of innate apoptotic immunity early transcriptional responses

The immunomodulatory and anti-inflammatory effects elicited upon the specific recognition of apoptotic cells ${ }^{11}$ result primarily from the triggering of immediate-early transcriptional events in responding cells (both professional and non-professional phagocytes) that interact with them. ${ }^{5,10}$ These transcriptional effects include the repression of expression of some genes, and the induction of expression of others (see Table). Additional transcriptional and other responses (e.g., the induction of TGF $\beta$ expression ${ }^{13,15,69}$ ) ensue subsequently.

\section{IAI immediate-early transcriptional modulation}

\section{Repression}

Gene encoding:

TNFa

IL-6

IL-12

iNOS

\author{
References \\ 5,70 \\ 5,70 \\ 70-72 \\ 73. Pattabiraman et al., unpublished
}

Induction

Gene encoding:

IL-10

Arg-II

72,74; Pattabiraman et al., unpublished

phosphatidylserine (PS), an anionic phospholipid cloistered normally in the inner leaflet of the plasma membrane of viable cells and externalized during the process of apoptosis, serves as a determinant for this engulfment process. ${ }^{4}$ Blockade of apoptotic cell engulfment can be affected by the masking of PS through the pre-binding of annexin V to exposed PS on the apoptotic cell surface. ${ }^{9}$ Immune pathologies attributed to the failure to promptly clear apoptotic cells, especially including chronic inflammation and autoimmunity characteristic of systemic lupus erythematosus and rheumatic diseases (see Savill et al. ${ }^{6}$ and Birge et al. ${ }^{8}$ and citations therein) may rather reflect deficiencies in apoptotic cell interactions and IAI.

$\mathrm{IAI}$ is triggered upon apoptotic recognition, independently of engulfment. Indeed, non-phagocytic cells recognize and respond to apoptotic corpses as well as phagocytic responders. ${ }^{5,10}$ The apoptotic suppression of inflammation is exerted principally on the level of transcription, ${ }^{5}$ and involves both the repression of the expression of genes encoding pro-inflammatory cytokines (such as tumor necrosis factor- $a$ (TNF $a$ ) and interleukin (IL)-6), and the induction of gene expression for anti-inflammatory cytokines (such as IL-10). Primary elements of this extensive repertoire are listed in Box 1. In contrast to its role in engulfment, ${ }^{4} \mathrm{PS}$ is not a determinant for the recognition-dependent initiation of IAI. ${ }^{10,11}$ The cell surface determinant(s) involved in initiating IAI are not masked by annexin $\mathrm{V}$, rather, they are protease-sensitive. ${ }^{12}$ In addition, they are evolutionarily conserved, resident in all cells prior to cell death, and become surface-exposed (and susceptible to proteolytic digestion) during the process of apoptosis. We have referred to these characteristics as SUPER (surface-exposed (during apoptotic cell death), ubiquitously expressed (on all apoptotic cells), proteasesensitive, evolutionarily conserved, and resident normally in viable cells). ${ }^{12}$ (Subsequent responses, including the production of anti-inflammatory factors and cytokines (such as transforming growth factor- $\beta$; TGF $\beta$ ), which may maintain and/or enhance IAI, are linked to PS-dependent apoptotic cell internalization ${ }^{13-15}$.)

Pathogens appear to exploit aspects of the host response elicited by apoptotic cells as a means of enhancing their pathogenic life cycle. Such apoptotic mimicry has been characterized rigorously with several viruses ${ }^{16,17}$ and trypanosomatids. ${ }^{18-20}$ For example, viral internalization and the suppression of host immune responsiveness associated with vaccinia and hepatitis $B$ viruses appear to follow apoptoticlike mechanisms of PS-dependent macropinocytosis and antiinflammatory cytokine induction. Similarly, the internalization of the amastigotes from different species of Leishmania parasitic protists into mammalian macrophage hosts has been shown to occur via an amiloride-sensitive process, dependent on PS exposure and independent of immunoglobulin $\mathrm{F}_{\mathrm{C}}$ receptors. ${ }^{21}$ Trypanosomatid parasites such as Leishmania alternate between a free-living, flagellated promastigote form in insect vectors and an intracellular, unflaggelated amastigote form in infected mammalian hosts. Just as the anti-inflammatory milieu elicited by apoptotic cells enhances leishmanial growth, ${ }^{22}$ Leishmania themselves also lead to the induction of antiinflammatory cytokines in infected mammalian hosts. ${ }^{23}$ Among these, it is striking that TGF $\beta$, in addition to suppressing host inflammatory responses, also serves as a stimulus for leishmanial growth. ${ }^{24}$ Especially under conditions of chronic Leishmania infection, systemic cytokine profiles in infected individuals resemble the apoptotic-like anti-inflammatory state. ${ }^{23}$ However, the specific triggering mechanism for antiinflammatory cytokine expression has not been elucidated.

Several molecules that function intracellularly as enzymes involved in glycolysis, especially a-enolase and glutaraldehyde 3-phosphate dehydrogenase (GAPDH), become externalized on the surface of apoptotic cells and have been identified among the conserved, protease-sensitive apoptotic cell surface determinants responsible for apoptotic recognition and the triggering of IAI. ${ }^{12}$ The complete glycolytic pathway is 


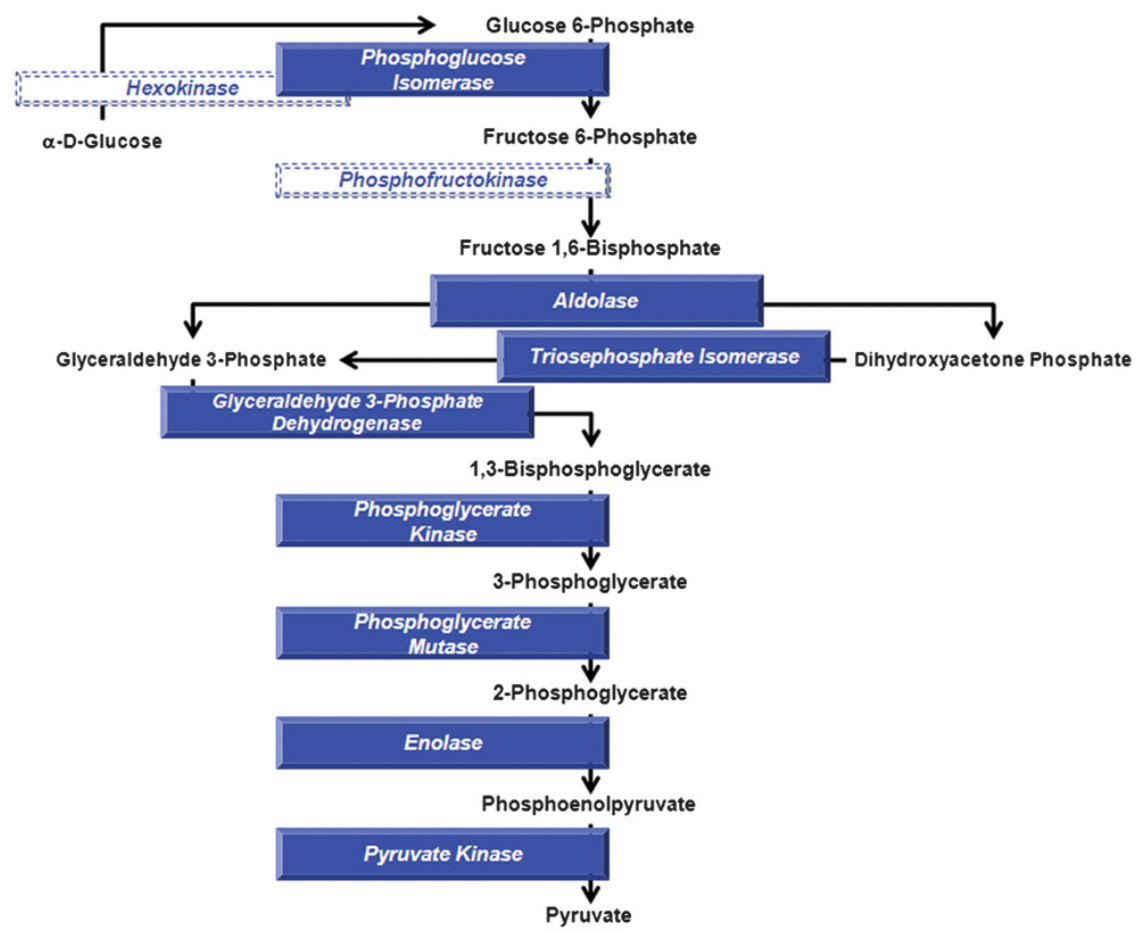

Figure 1 Apoptotic externalization of glycolytic enzyme molecules. Many of the protein species involved as enzymes in the intracellular glycolytic pathway of viable cells are enriched among membrane proteins of apoptotic cells and are exposed specifically on the apoptotic cell surface (shown in filled boxes). The externalization of these glycolytic enzyme molecules is a common early event during the process of apoptotic cell death. These externalized molecules fulfill SUPER criteria and are linked to the triggering of IAI (adapted from Ucker et al. ${ }^{12}$ )

delineated in Figure 1, and the glycolytic enzyme molecules that are externalized apoptotically are indicated. These glycolytic enzyme molecules exist among a surprisingly extensive array of cellular components, representing autoantigens, that are exposed on the surface of apoptotic cells ${ }^{25}$ it is likely that the absence of autoimmune reactivity normally is established and maintained through $\mid \mathrm{Al}^{3}{ }^{3}$ Biochemical analyses indicate that the externalized glycolytic enzyme molecules, including $a$-enolase and GAPDH, exist as peripheral membrane proteins in multimeric complexes (Palasiewicz, Pattabiraman, and Ucker, unpublished data).

The surface exposure of glycolytic enzymes has been noted previously with a variety of enteric bacteria and pathogens. ${ }^{26-33}$ Independent studies also have implicated externalized $a$-enolase and GAPDH on mammalian and pathogen surfaces as sites for plasminogen binding and subsequent activation by host or pathogen activities, ${ }^{26-28,30,31,34-36}$ and we have demonstrated that externalized glycolytic enzymes on the apoptotic cell surface, including $a$-enolase, also are sites for plasminogen binding. ${ }^{12}$ Although enhanced virulence has been attributed to the presumptive augmentation in mobility through matrix or fibrin clots associated with localized plasminogen activation following binding on the pathogen surface, ${ }^{37,38}$ no compelling physiological rationale exists for plasminogen binding on non-invasive bacteria and apoptotic cells. We have argued that the exposure of glycolytic enzymes on microorganisms reflects an exploitation of IAI through apoptotic mimicry, and that consequent immune suppression facilitates pathogenesis, as well as commensalism. ${ }^{12}$
Some microbial pathogens, such as the food-borne bacterium Listeria monocytogenes, ${ }^{39}$ trigger host cell death directly. Although several insightful studies have implicated a functionally significant role for the involvement of apoptotic cells in instances of pathogenesis such as these, ${ }^{40,41}$ the broader complexity and diversity of apoptotic and apoptoticlike events involved in enhancing microbial pathogenesis has not previously been appreciated fully.

\section{Apoptotic Subversion}

In the case of Listeria monocytogenes, a virulent and lethal facultative intracellular bacterial pathogen, ${ }^{39,42}$ the induction of host cell apoptosis appears to be important for bacterial pathogenicity. Listeria monocytogenes long has been known to trigger the apoptotic death of mammalian cells. Although lymphocytes are not critical for the in vivo replication and pathogenesis of Listeria monocytogenes, they are extensively induced to undergo apoptotic death during Listeria monocytogenes infection. ${ }^{41}$ This has been of interest within the field of cell death, especially because of the involvement of a bacterial pore-forming molecule (listeriolysin $\mathrm{O}^{43}$ ), inflammatory cytokines, including Type I (especially $\beta$ ) Interferon (which potentiates listeriolysin $\mathrm{O}$ susceptibility ${ }^{44}$ ), and the relation to pyroptosis. ${ }^{45}$ It had not been clear, however, that host cell death was of relevance to the life cycle of the bacterium as a mammalian pathogen.

Previous work $^{41}$ had suggested that Listeria monocytogenes-induced apoptotic lymphocyte cell death serves to 

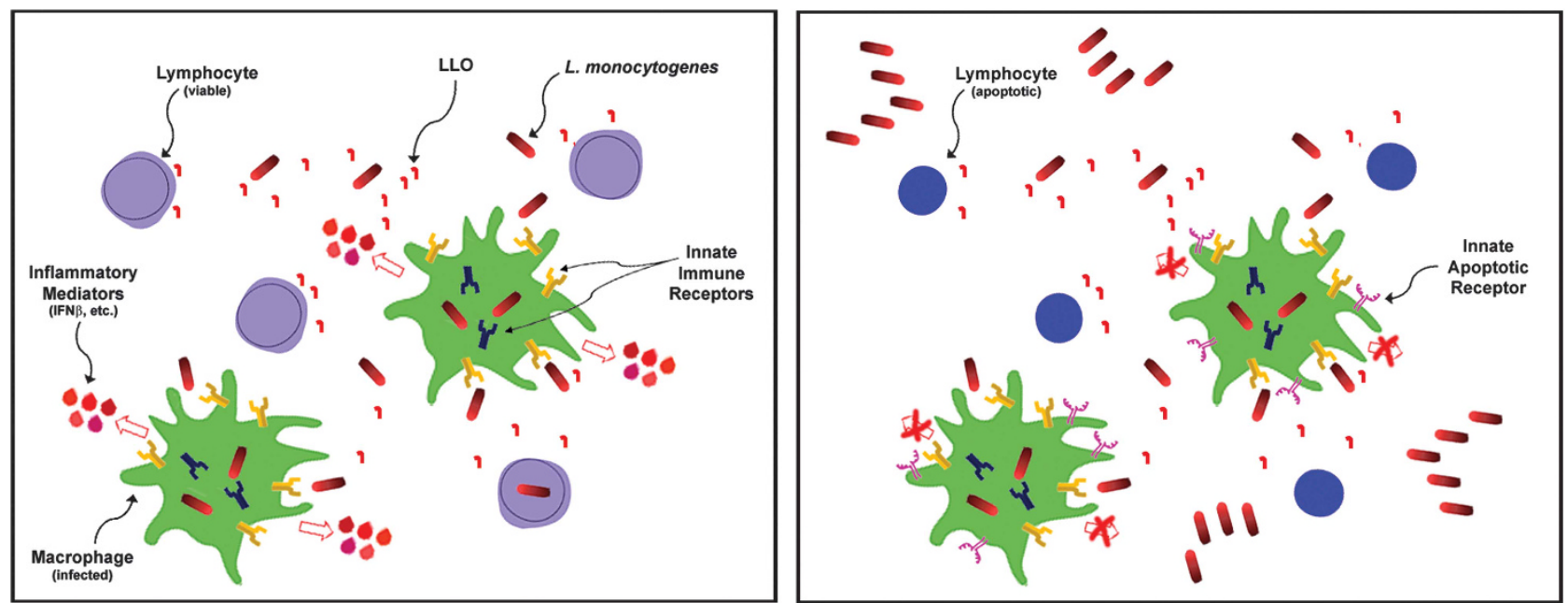

Figure 2 Subversion of apoptosis and IAI by Listeria monocytogenes. A simplified model schematizes the competing, antagonistic responses elicited in the host upon infection by Listeria monocytogenes. The induction of host cell apoptosis by Listeria monocytogenes in the first phase of infection (Left panel) antagonizes pro-inflammatory responses subsequently, leading to an anti-inflammatory phase (right panel) during which Listeria monocytogenes replication and pathogenesis are enhanced. Left panel: Listeria monocytogenes secretes a pore-forming, apoptosis-inducing molecule, Listeriolysin O $\left(L L 0^{66}\right)$. LLO is represented as small hook-shaped symbols, the long arm of which being the membrane-insinuating region, containing the cholesterol-binding motif. In addition to eliciting innate immune responses (such as the release of pro-inflammatory cytokines) via the triggering of extracellularly exposed innate immune receptors, such toll-like receptor 2 (TLR2, which senses bacterial lipoteichoic acid ${ }^{67}$ ), Listeria monocytogenes triggers intracellular innate immune receptors, such as Stimulator of Interferon Genes (STING; which senses released cyclic di-adenosine monophosphat ${ }^{68}$ ), stimulating the production and secretion of type I interferons (especially interferon- $\beta$ ). Extracellularly exposed and intracellular innate immune receptors are represented as simple structures with a concave binding pocket. The observed requirement for type I interferon (and the corresponding type I interferon receptor (IFN- $\alpha \beta \mathrm{R}$ )) in the lymphocyte-dependent enhancement of $L$ isteria monocytogenes pathogenesis ${ }^{43}$ reflects the ability of this family of cytokines to sensitize lymphocytes to LLO-dependent apoptosis. ${ }^{44}$ Right panel: Recognition by macrophages (among other cell types) of the apoptotic host lymphocytes induced to die upon Listeria monocytogenes infection (see left panel) via a putative innate apoptotic receptor leads to anti-inflammatory responses characteristic of IAI, including the repression of pro-inflammatory cytokine expression (Box 1). The induction of anti-inflammatory cytokine expression, which also ensues (Box 1), is not pictured in this figure. The innate apoptotic receptor is represented as a hypothetical heterodimeric structure

facilitate pathogenicity. Mice lacking lymphocytes (and consequent apoptotic lymphocytes induced during infection) were found to be less susceptible to Listeria monocytogenes infection than were lymphocyte-replete, wild-type mice. The introduction of normal lymphocyte populations into genetically deficient animals restored pathogen susceptibility to normal (elevated) levels. These results, at first glance, seem paradoxical: lymphocytes are effectors of adaptive immunity and lymphocyte-deficient animals are immunocompromised generally. However, in light of the profound immunosuppressive responses elicited by apoptotic cells, it is reasonable to posit that the apoptotic lymphocytes induced by Listeria monocytogenes suppress host innate immune responses that would be directed against the bacterial infection (as modeled in Figure 2). Indeed, we have confirmed that exogenous apoptotic (and not necrotic) lymphocytes suppress host inflammatory responses and enhance the growth and pathogenicity of the bacterium in vivo (Pattabiraman, Palasiewicz, Visvabharathy, Freitag, and Ucker (2016), in preparation).

Independent studies with a sepsis model of bacterial pathogenicity ('cecal ligation and puncture') also indicate that the induction of apoptotic cell death endogenously, or the introduction in vivo of exogenous apoptotic cells, furthers pathogenicity. ${ }^{40,46}$ Apoptotic cells have been shown to exacerbate the proliferation of Trypanosome parasites, as well. ${ }^{47}$ These varied cases illustrate the subversion of apoptosis and apoptotic immunity in serving to enhance microbial pathogenesis.

\section{Apoptotic Mimicry}

The protist parasite Leishmania amazonensis exhibits what is perhaps the most revealing examples of apoptotic mimicry, where apoptotic-like PS exposure facilitates infective internalization ${ }^{21}$ and glycolytic enzyme exposure serves in host immune suppression. It is, as yet, unclear whether any one externalized molecule is sufficient for the triggering of IAI or whether multiple proteins necessarily function in concert for this purpose. Consequently, the detailed significance for IAI of the exposure of multiple glycolytic enzymes in mammalian cells and, correspondingly, how the process of protein externalization during apoptotic cell death functions selectively remain unresolved.

The biology of trypanosomatids presents a provocative context in which to explore this issue. The subcellular compartmentalization of glycolysis in trypanosomatids is fundamentally different than in all other eukaryotes, where glycolysis ensues cytoplasmically. In trypanosomatids, the majority of glycolytic enzymes are contained in unusual peroxisome-like organelles termed 'glycosomes'; only the terminal three glycolytic enzymes are cytosolic ${ }^{48,49}$ (see Figure 3). Thus in trypanosomatids, GAPDH and enolase exist in distinct intracellular locales and are unassociated.

Glycolytic enzyme molecules have been reported to be externalized by Leishmania species and other trypanosomatids. ${ }^{50,51}$ (The functional significance of plasminogen binding with respect to Leishmania pathogenesis has not been established definitively. ${ }^{52}$ ) Proteomic analysis indicates that 


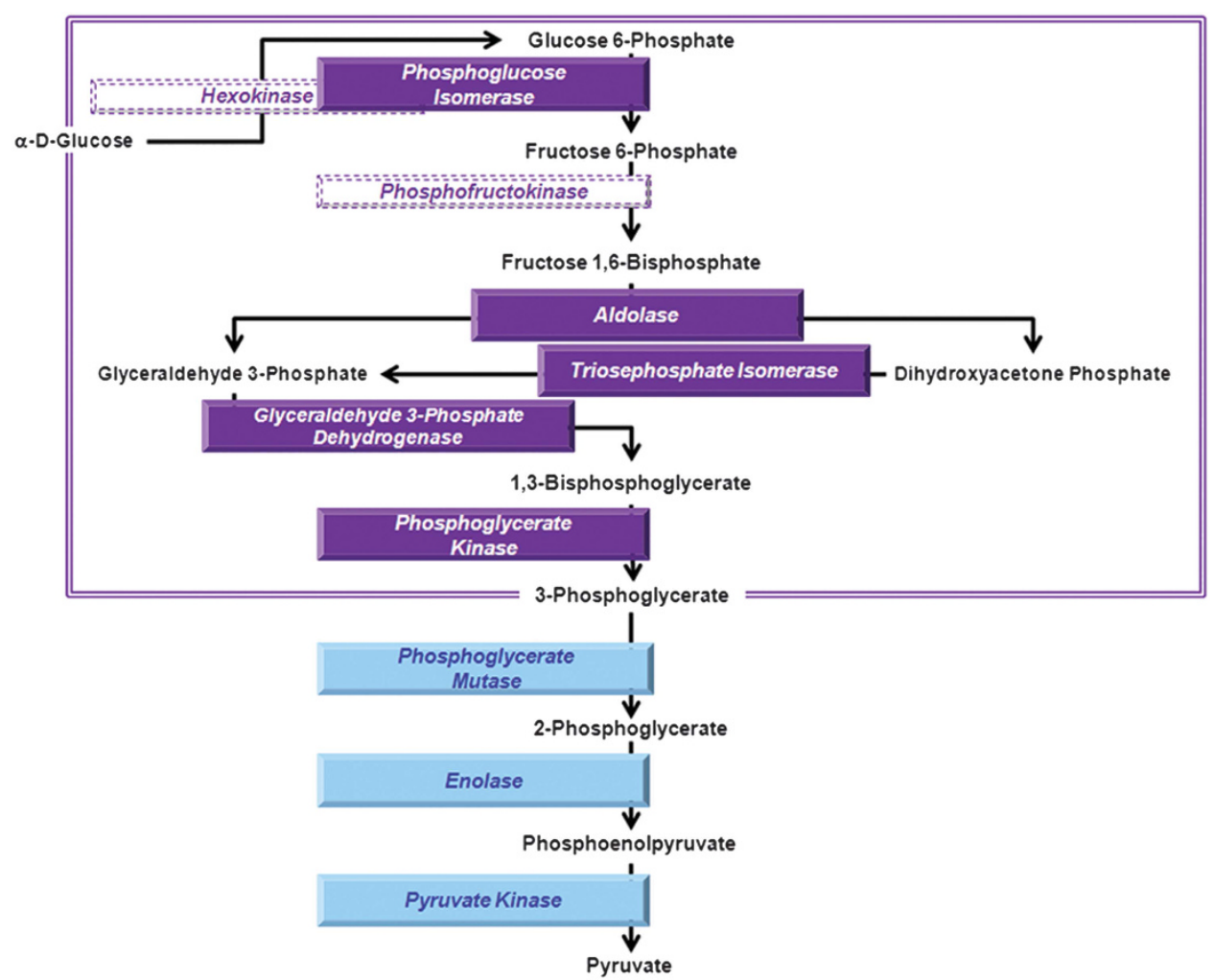

Figure 3 Glycosomal localization of glycolytic enzymes. Enzymes and intermediates of glycolysis that are found within and without the glycosome ${ }^{48,49}$ are diagrammed here. Glycosomes are intracellular peroxisome-like organelles of trypanosomatids, constrained by a single lipid bilayer membrane (represented by a double solid line), within which the proximal steps of glycolysis ensue. Glycosomal contents vary during the heteroxenous trypanosomatid life cycle, and other metabolic processes (including glycerol catabolism) also are localized within. ${ }^{49}$ Intraglycosomal glycolytic enzymes are shown as darker (purple) boxes; extraglycosomal (cytosolic) glycolytic enzymes are shown as lighter (blue) boxes. Filled boxes denote those glycolytic enzymes whose mammalian homologs are externalized on the apoptotic cell surface (see Figure 1)

enolase is a predominant surface-exposed Leishmania molecule. ${ }^{53}$ As in the case of glycolytic enzyme molecule exposure associated with apoptosis, externalized Leishmania enolase has no enzymatic activity. ${ }^{12,50,53}$ In this case, enolase appears to be regulated by posttranslational modification (dependent on oligopeptidase $\mathrm{B}^{53}$ ).

We have found that the infective form of the protist parasite Leishmania amazonensis externalizes extraglycosomal enolase on its cell surface in the absence of intraglycosomal glycolytic enzyme molecules (Wanderley, Gomes, Vieira, Barcinski, Meyer Fernandez, and Ucker (2016), in preparation). This is consistent with the lack of association of glycosomal and non-glycosomal enzymes reported in Trypanosoma cruzi, in which the externalization of extraglycosomal enolase $^{50}$ appears to occur without the involvement of intraglycosomal triosephosphate isomerase. ${ }^{54}$ Beyond the evolutionary significance of enolase externalization, this may suggest that other glycolytic enzyme molecules are dispensable for the triggering of IAI.

This work, which documents the direct and extensive apoptotic mimicry accomplished by these protist pathogens, reinforces the role of glycolytic enzyme externalization in the triggering of IAI. Moreover, the evolutionarily distant trypanosomatid biology provides a fortuitous context with which to refine our view of essential IAI determinants.

\section{Reprogrammed Cell Death}

A growing list of microbes has been recognized that exploit apoptosis and IAI, including both Gram-positive and Gram-negative bacteria as well as non-bacterial pathogens. ${ }^{18,21,41,55-64}$ Viruses exploit apoptotic processes as well, especially reducing the death of virally infected cells to facilitate intracellular viral replication. The viral reprogramming of cell death, in contrast, reflects a distinct approach.

As with many viral types, adenoviruses induce cell death in infected cells. These viruses encode a death-inhibitory gene product, which prevents rapid death, promotes viral replication, and results ultimately in a seemingly non-apoptotic form of cell death. The death-inhibitory protein, functionally equivalent to mammalian death-inhibitory $\mathrm{Bcl}-2$, is the $19 \mathrm{kDa}$ product of the adenovirus E1B gene (E1B $19 \mathrm{~K}$ ).

Remarkably, the immunosuppressive activities of cells dying as a result of adenovirus infections were found to be exactly the opposite of 'typical' apoptotic and necrotic cells. ${ }^{65}$ That is, apoptotic-like cells, dying as a result of infection with an E1B 19 K-deficient adenovirus, were not immunosuppressive, and non-apoptotic cells, dying as a result of wild-type adenoviral infection, were immunosuppressive. This 'reversed' behavior was attributable genetically to E1B $19 \mathrm{~K}$. That authentic Bcl-2 could substitute for E1B $19 \mathrm{~K}$, but that it does not program such a reversed behavior in the context of 
uninfected mammalian cells suggests the additional contribution of other adenoviral gene(s).

It is clear that the inhibition of infection-induced death, as well as death reprogramming and associated immunomodulation, are beneficial to adenoviral pathogenicity. ${ }^{65}$ The complete genetic basis of adenoviral cell death reprogramming and its mechanism remain to be elucidated. Similarly, whether other viruses direct cell death reprogramming remains unexplored.

\section{Conclusion}

Whereas cell death once was considered to provide the answer to the issue of how the fate of cells that become inappropriate is resolved, we now understand that, more than cell death itself, it is the interaction of those dead cells with neighboring and other viable cells (leading to their clearance, the attenuation of inflammation, and tissue homeostasis generally (including wound healing)) that is determinative of resolution. Dysfunctions in those interactions are associated with immune (especially autoimmune and inflammatory) pathologies and neurodegenerative diseases. In this context, it may not be surprising that some microbes subvert these processes and enhance pathogenesis.

Although the above cases highlight distinct means used by microbial pathogens to exploit IAI and enhance pathogenicity, it is not clear that any single manipulative pathway ever is utilized in isolation. Microbial pathogenesis involves varied strategies including the utilization of a complexity of targeted apoptosis-specific and apoptotic-related manipulations. We speculate, as well, that apoptotic mimicry by indigenous microbes engages IAI locally and may facilitate commensalism. A detailed understanding of these modes of pathogenic exploitation of $\mid \mathrm{AI}$ is of profound importance for a more comprehensive appreciation of mechanisms of pathogenicity, and is likely to be particularly insightful for a fuller understanding of IAI as well. In particular, the molecular dissection of the mechanisms by which the pathogenic exploitation of IAI is affected holds promise for identifying novel targets for therapeutic intervention to enhance anti-microbial immune responsiveness.

\section{Conflict of Interest}

The author declares no conflict of interest.

Acknowledgements. I am grateful to my many colleagues for provocative and insightful discussions. I am particularly indebted to Drs Marcello André Barcinski, Nancy Freitag, João Luiz Mendes Wanderley, and José Roberto Meyer Fernandes. I am very appreciative of the thoughtful and dedicated work of Karol Palasiewicz and Drs Goutham Pattabiraman, Marta Gomes, and Lisvane Paes Vieira. Work cited here was supported in part by a J. William Fulbright scholarship, an award from the UIC Campus Research Board, and NIH grant AG029633 to DSU.

1. Lederer JA, Rodrick ML, Mannick JA. The effects of injury on the adaptive immune response. Shock 1999; 11: 153-159.

2. Savill J. Phagocytic docking without shocking. Nature 1998; 392: 442-443.

3. Ucker DS. Innate apoptotic immunity: a potent immunosuppressive response repertoire elicited by specific apoptotic cell recognition In:Krysko DV, Vandenabeele P (eds). Phagocytosis of Dying Cells: from Molecular Mechanisms to Human Diseases. Springer: Berlin, New York, 2009 pp 163-187.
4. Fadok VA, Voelker DR, Campbell PA, Cohen JJ, Bratton DL, Henson PM. Exposure of phosphatidylserine on the surface of apoptotic lymphocytes triggers specific recognition and removal by macrophages. J Immunol 1992; 148: 2207-2216.

5. Cvetanovic M, Ucker DS. Innate immune discrimination of apoptotic cells: repression of proinflammatory macrophage transcription is coupled directly to specific recognition. $J$ Immunol 2004; 172: 880-889.

6. Savill J, Dransfield I, Gregory C, Haslett C. A blast from the past: clearance of apoptotic cells regulates immune responses. Nat Rev Immunol 2002; 2: 965-975.

7. Hoffmann PR, deCathelineau AM, Ogden CA, Leverrier Y, Bratton DL, Daleke DL et al. Phosphatidylserine (PS) induces PS receptor-mediated macropinocytosis and promotes clearance of apoptotic cells. J Cell Biol 2001; 155: 649-660.

8. Birge RB, Ucker DS. Innate apoptotic immunity: the calming touch of death. Cell Death Differ 2008; 15: 1096-1102.

9. Krahling S, Callahan MK, Williamson P, Schlegel RA. Exposure of phosphatidylserine is a general feature in the phagocytosis of apoptotic lymphocytes by macrophages. Cell Death Differ 1999; 6: 183-189.

10. Cvetanovic M, Mitchell JE, Patel V, Avner BS, Su Y, van der Saag PT et al. Specific recognition of apoptotic cells reveals a ubiquitous and unconventional innate immunity. J Biol Chem 2006; 281: 20055-20067.

11. Cocco RE, Ucker DS. Distinct modes of macrophage recognition for apoptotic and necrotic cells are not specified exclusively by phosphatidylserine exposure. Mol Biol Cell 2001; 12 919-930.

12. Ucker DS, Jain MR, Pattabiraman G, Palasiewicz K, Birge RB, Li H. Externalized glycolytic enzymes are novel, conserved, and early biomarkers of apoptosis. J Biol Chem 2012; 287 : 10325-10343.

13. Xiao YQ, Freire-de-Lima CG, Schiemann WP, Bratton DL, Vandivier RW, Henson PM Transcriptional and translational regulation of TGF- $\beta$ production in response to apoptotic cells. J Immunol 2008; 181: 3575-3585.

14. Fadok VA, Bratton DL, Konowal A, Freed PW, Westcott JY, Henson PM. Macrophages that have ingested apoptotic cells in vitro inhibit proinflammatory cytokine production through autocrine/paracrine mechanisms involving TGF- $\beta$, PGE2, and PAF. J Clin Invest 1998; 101 890-898.

15. McDonald PP, Fadok VA, Bratton D, Henson PM. Transcriptional and translational regulation of inflammatory mediator production by endogenous TGF- $\beta$ in macrophages that have ingested apoptotic cells. J Immunol 1999; 163: 6164-6172.

16. Vanlandschoot $P$, Leroux-Roels $G$. Viral apoptotic mimicry: an immune evasion strategy developed by the hepatitis B virus? Trends Immunol 2003; 24: 144-147.

17. Mercer J, Helenius A. Vaccinia virus uses macropinocytosis and apoptotic mimicry to enter host cells. Science 2008; 320: 531-535.

18. de Freitas Balanco JM, Moreira MEC, Bonomo A, Bozza PT, Amarante-Mendes G, Pirmez C et al. Apoptotic mimicry by an obligate intracellular parasite downregulates macrophage microbicidal activity. Curr Biol 2001; 11: 1870-1873.

19. Barcinski MA, Moreira ME, Balanco JM, Wanderley JL, Bonomo AC. The role of apoptotic mimicry in host-parasite interplay: is death the only alternative for altruistic behavior? Kinetoplastid Biol Dis 2003; 2: 6-7.

20. Wanderley JL, Benjamin A, Real F, Bonomo A, Moreira ME, Barcinski MA. Apoptotic mimicry: an altruistic behavior in host/Leishmania interplay. Braz J Med Biol Res 2005; 38 : 807-812.

21. Wanderley JL, Moreira ME, Benjamin A, Bonomo AC, Barcinski MA. Mimicry of apoptotic cells by exposing phosphatidylserine participates in the establishment of amastigotes of Leishmania (L) amazonensis in mammalian hosts. J Immunol 2006; 176: 1834-1839.

22. Afonso L, Borges VM, Cruz H, Ribeiro-Gomes FL, DosReis GA, Dutra AN et al. Interactions with apoptotic but not with necrotic neutrophils increase parasite burden in human macrophages infected with Leishmania amazonensis. J Leukoc Biol 2008; 84: 389-396.

23. de Oliveira $\mathrm{Cl}$, Brodskyn $\mathrm{Cl}$. The immunobiology of Leishmania braziliensis infection. Front Immunol 2012; 3: 145.

24. Barral A, Barral-Netto M, Yong EC, Brownell CE, Twardzik DR, Reed SG. Transforming growth factor $\beta$ as a virulence mechanism for Leishmania braziliensis. Proc Natl Acad Sci USA 1993; 90: 3442-3446.

25. Cocca BA, Cline AM, Radic MZ. Blebs and apoptotic bodies are B cell autoantigens $\mathrm{J}$ Immunol 2002; 169: 159-166.

26. Pancholi V, Fischetti VA. A major surface protein on group A streptococci is a glyceraldehyde-3-phosphate-dehydrogenase with multiple binding activity. J Exp Med 1992; 176: 415-426.

27. Bergmann S, Rohde M, Chhatwal GS, Hammerschmidt S. $\alpha$-Enolase of Streptococcus pneumoniae is a plasmin(ogen)-binding protein displayed on the bacterial cell surface. Mo Microbiol 2001; 40: 1273-1287.

28. Bergmann S, Rohde M, Hammerschmidt S. Glyceraldehyde-3-phosphate dehydrogenase of Streptococcus pneumoniae is a surface-displayed plasminogen-binding protein. Infect Immun 2004; 72: 2416-2419.

29. Lama A, Kucknoor A, Mundodi V, Alderete JF. Glyceraldehyde-3-phosphate dehydrogenase is a surface-associated, fibronectin-binding protein of Trichomonas vaginalis. Infect Immun 2009; 77: 2703-2711.

30. Pancholi V, Fischetti VA. $\alpha$-Enolase, a novel strong plasmin(ogen) binding protein on the surface of pathogenic streptococci. J Biol Chem 1998; 273: 14503-14515.

31. Bhowmick IP, Kumar N, Sharma S, Coppens I, Jarori GK. Plasmodium falciparum enolase: stage-specific expression and sub-cellular localization. Malar J 2009; 8: 179 
32. Gil-Navarro I, Gil ML, Casanova M, O'Connor JE, Martinez JP, Gozalbo D. The glycolytic enzyme glyceraldehyde-3-phosphate dehydrogenase of Candida albicans is a surface antigen. J Bacteriol 1997; 179: 4992-4999.

33. Goudot-Crozel V, Caillol D, Djabali M, Dessein AJ. The major parasite surface antigen associated with human resistance to schistosomiasis is a $37-\mathrm{kD}$ glyceraldehyde-3P. dehydrogenase. J Exp Med 1989; 170: 2065-2080.

34. Miles LA, Dahlberg CM, Plescia J, Felez J, Kato K, Plow EF. Role of cell-surface lysines in plasminogen binding to cells: identification of $\alpha$-enolase as a candidate plasminogen receptor. Biochemistry 1991; 30: 1682-16891.

35. Plow EF, Herren T, Redlitz A, Miles LA, Hoover-Plow JL. The cell biology of the plasminogen system. FASEB J 1995; 9: 939-945.

36. Félez J, Miles LA, Fábregas $P$, Jardí M, Plow EF, Lijnen RH. Characterization of cellular binding sites and interactive regions within reactants required for enhancement of plasminogen activation by IPA on the surface of leukocytic cells. Thromb Haemost 1996; 76: 577-584.

37. Jong AY, Chen SH, Stins MF, Kim KS, Tuan T-L, Huang S-H. Binding of Candida albicans enolase to plasmin(ogen) results in enhanced invasion of human brain microvascular endothelial cells. J Med Microbiol 2003; 52: 615-622.

38. Sun H, Ringdahl U, Homeister JW, Fay WP, Engleberg NC, Yang AY et al. Plasminogen is a critical host pathogenicity factor for group A streptococcal infection. Science 2004; 305 : 1283-1286.

39. Dussurget O, Pizarro-Cerda J, Cossart P. Molecular determinants of Listeria monocytogenes virulence. Annu Rev Microbiol 2004; 58: 587-610.

40. Hotchkiss RS, Chang KC, Grayson MH, Tinsley KW, Dunne BS, Davis CG et al Adoptive transfer of apoptotic splenocytes worsens survival, whereas adoptive transfer of necrotic splenocytes improves survival in sepsis. Proc Natl Acad Sci USA 2003; 100: 6724-6729.

41. Carrero JA, Calderon B, Unanue ER. Lymphocytes are detrimental during the early innate immune response against Listeria monocytogenes. J Exp Med 2006; 203: 933-940.

42. Freitag NE, Port GC, Miner MD. Listeria monocytogenes - from saprophyte to intracellular pathogen. Nat Rev Microbiol 2009; 7: 623-628.

43. Carrero JA, Calderon B, Unanue ER. Listeriolysin O from Listeria monocytogenes is a lymphocyte apoptogenic molecule. J Immunol 2004; 172: 4866-4874.

44. Carrero JA, Calderon B, Unanue ER. Type I interferon sensitizes lymphocytes to apoptosis and reduces resistance to Listeria infection. J Exp Med 2004; 200: 535-540.

45. Kim S, Bauernfeind F, Ablasser A, Hartmann G, Fitzgerald KA, Latz E et al. Listeria monocytogenes is sensed by the NLRP3 and AIM2 inflammasome. Eur J Immunol 2010; 40: 1545-1551.

46. Hotchkiss RS, McConnell KW, Bullok K, Davis CG, Chang KC, Schwulst SJ et al. TAT-BH4 and TAT-BCl- $\mathrm{X}_{\mathrm{L}}$ peptides protect against sepsis-induced lymphocyte apoptosis in vivo. J Immunol 2006; 176: 5471-5477.

47. Freire-de-Lima CG, Nascimento DO, Soares MB, Bozza PT, Castro-Faria-Neto HC, de Mello FG et al. Uptake of apoptotic cells drives the growth of a pathogenic trypanosome in macrophages. Nature 2000; 403: 199-203.

48. Opperdoes FR. The glycosome of trypanosomes and Leishmania. Biochem Soc Trans 1990; 18: $729-731$.

49. Michels PA, Bringaud F, Herman M, Hannaert V. Metabolic functions of glycosomes in trypanosomatids. Biochim Biophys Acta 2006; 1763: 1463-1477.

50. Avilán L, Gualdrón-López M, Quiñones W, González-González L, Hannaert V, Michels PA et al. Enolase: a key player in the metabolism and a probable virulence factor of trypanosomatid parasites-perspectives for its use as a therapeutic target. Enzyme Res 2011; 2011: 932549 .

51. Vanegas G, Quinones W, Carrasco-Lopez C, Concepcion JL, Albericio F, Avilán L. Enolase as a plasminogen binding protein in Leishmania mexicana. Parasitol Res 2007; 101: 1511-1516.

52. Maldonado J, Marina C, Puig J, Maizo Z, Avilán L. A study of cutaneous lesions caused by Leishmania mexicana in plasminogen-deficient mice. Exp Mol Pathol 2006; 80: 289-294.

53. Swenerton RK, Zhang S, Sajid M, Medzihradszky KF, Craik CS, Kelly BL et al. The oligopeptidase B of Leishmania regulates parasite enolase and immune evasion. J Biol Chem 2011; 286: 429-440.
54. Cortés-Figueroa AA, Pérez-Torres A, Salaiza N, Cabrera N, Escalona-Montaño A, Rondán A et al. A monoclonal antibody that inhibits Trypanosoma cruzi growth in vitro and its reaction with intracellular triosephosphate isomerase. Parasitol Res 2008; 102: 635-643.

55. Bantel H, Sinha B, Domschke W, Peters G, Schulze-Osthoff K, Jänicke RU. $\alpha$-Toxin is a mediator of Staphylococcus aureus-induced cell death and activates caspases via the intrinsic death pathway independently of death receptor signaling. J Cell Biol 2001; 155: 637-648.

56. Braun JS, Sublett JE, Freyer D, Mitchell TJ, Cleveland JL, Tuomanen El et al. Pneumococcal pneumolysin and $\mathrm{H}_{2} \mathrm{O}_{2}$ mediate brain cell apoptosis during meningitis. J Clin Invest 2002; 109: 19-27.

57. Jonas D, Walev I, Berger T, Liebetrau M, Palmer M, Bhakdi S. Novel path to apoptosis: small transmembrane pores created by Staphylococcal alpha-toxin in T lymphocytes evoke internucleosomal DNA degradation. Infect Immun 1994; 62: 1304-1312.

58. Kemp K, Bruunsgaard H, Skinhøj P, Klarlund Pedersen B. Pneumococcal infections in humans are associated with increased apoptosis and trafficking of type 1 cytokine-producing T cells. Infect Immun 2002; 70: 5019-5025.

59. Mahida YR, Galvin A, Makh S, Hyde S, Sanfilippo L, Borriello SP et al. Effect of Clostridium difficile toxin $A$ on human colonic lamina propria cells: early loss of macrophages followed by T-cell apoptosis. Infect Immun 1998; 66: 5462-5469.

60. Monack DM, Mecsas J, Bouley D, Falkow S. Yersinia-induced apoptosis in vivo aids in the establishment of a systemic infection of mice. J Exp Med 1998; 188: 2127-2137.

61. Popov SG, Villasmil R, Bernardi J, Grene E, Cardwell J, Popova T et al. Effect of Bacillus anthracis lethal toxin on human peripheral blood mononuclear cells. FEBS Lett 2002; 527: 211-215.

62. Ulett GC, Adderson EE. Regulation of apoptosis by Gram-positive bacteria: mechanistic diversity and consequences for immunity. Current Immunol Rev 2006; 2: 119-141.

63. Zamboni DS, Rabinovitch M. Phagocytosis of apoptotic cells increases the susceptibility of macrophages to infection with Coxiella burnetii phase II through down-modulation of nitric oxide production. Infect Immun 2004; 72: 2075-2080.

64. Benoit M, Ghigo E, Capo C, Raoult D, Mege JL. The uptake of apoptotic cells drives Coxiella burnetii replication and macrophage polarization: a model for $Q$ fever endocarditis. PLOS Pathog 2008; 4: e1000066.

65. Radke JR, Grigera F, Ucker DS, Cook JL. Adenovirus E1B $19 \mathrm{~K}$ protein modulates innate immunity through apoptotic mimicry. J Virol 2014; 88: 2658-2669.

66. Hamon MA, Ribet D, Stavru F, Cossart P. Listeriolysin O, the Swiss army knife of Listeria. Trends Microbiol 2012; 20: 360-368.

67. Takeuchi O, Hoshino K, Kawai T, Sanjo H, Takada H, Ogawa T et al. Differential roles of TLR2 and TLR4 in recognition of gram-negative and gram- positive bacterial cell wall components. Immunity 1999; 11: 443-451.

68. Archer KA, Durack J, Portnoy DA. STING-dependent type I IFN production inhibits cellmediated immunity to Listeria monocytogenes. PLoS Pathog 2014; 10: e1003861.

69. Johann AM, Weigert A, Eberhardt W, Kuhn AM, Barra V, von Knethen A et al. Apoptotic cellderived sphingosine-1-phosphate promotes HuR-dependent cyclooxygenase-2 mRNA stabilization and protein expression. J Immunol 2008; 180: 1239-1248.

70. Ipseiz N, Uderhardt S, Scholtysek C, Steffen M, Schabbauer G, Bozec A et al. The nuclear receptor Nr4a1 mediates anti-inflammatory effects of apoptotic cells. J Immunol 2014; 192 : 4852-4858.

71. Kim S, Elkon KB, Ma X. Transcriptional suppression of interleukin-12 gene expression following phagocytosis of apoptotic cells. Immunity 2004; 21: 643-653.

72. A-Gonzalez N, Bensinger SJ, Hong C, Beceiro S, Bradley MN, Zelcer N et al. Apoptotic cells promote their own clearance and immune tolerance through activation of the nuclear receptor LXR. Immunity 2009; 31: 245-258.

73. Johann AM, Barra V, Kuhn A-M, Weigert A, von Knethen A, Brüne B. Apoptotic cells induce arginase II in macrophages, thereby attenuating NO production. FASEB $\mathrm{J} 2007 ; 21$ : 2704-2712.

74. Chung EY, Liu J, Homma Y, Zhang Y, Brendolan A, Saggese $M$ et al. Interleukin-10 expression in macrophages during phagocytosis of apoptotic cells is mediated by homeodomain proteins Pbx1 and Prep-1. Immunity 2007; 27: 952-964.

75. Barra V, Kuhn A-M, von Knethen A, Weigert A, Brüne B. Apoptotic cell-derived factors induce arginase II expression in murine macrophages by activating ERK5/CREB. Cell Mol Life Sci 2011; 68: 1815-1827. 